\title{
METADADOS E ARQUITETURAS DE MEMÓRIA EM AMBIENTES PROGRAMÁVEIS
}

\author{
Carlos Henrique Rezende Falci*
}

\begin{abstract}
RESUMO: O propósito desse artigo é discutir como a criação de memórias coletivas, em ambientes programáveis e com uso de metadados, provoca o intercruzamento das memórias comunicativas com as memórias culturais e permite o surgimento de arquiteturas de memória, aqui denominadas memórias culturais em permanente estado de construção. Os projetos analisados aqui parecem indicar que as memórias mediadas tecnologicamente, com uso de metadados, não são simplesmente formas de registro amplificadas, mas sim se apresentam como uma criação de memórias culturais a partir de uma poética baseada em metadados. Para compreender melhor a relação entre memórias culturais e comunicativas, o artigo apresenta e discute questões relativas ao caráter coletivo de registro desses tipos de memórias. A pesquisa aqui apresentada faz parte de um projeto de pesquisa mais amplo, financiado pela FAPEMIG, e cujo objetivo final é produzir experimentos que testem a hipótese que ora se discute, sobre novas arquiteturas para memórias culturais em ambientes programáveis.
\end{abstract}

PALAVRAS-CHAVE: Memórias culturais. Memórias comunicativas. Ambientes programáveis. Metadados.

\section{Introdução}

As memórias coletivas (HALBWACHS, 2006; SANTOS, 2001) produzidas em ambientes programáveis podem ser entendidas como produção de novos acontecimentos (BROCKMEIER, 2010), uma vez que se baseiam em poéticas de programação, em uma cultura de remixabilidade, e na lógica de funcionamento de redes sociotécnicas. (COUCHOT, 2003; MUSSO, 2004; SANTAELLA, 2008; SERRES, 1990) O que parece acontecer, derivado dessa mistura, não é mais um resgate da memória, mas uma construção incessante de memórias culturais que se aproximam de uma memória comunicativa. (ASSMAN, 2005; FEATHERSTONE, 2000) Os objetos mediados de memória ajudam a formar, a produzir relações entre acontecimentos, mais do que simplesmente fixar

\footnotetext{
*Universidade Federal de Minas Gerais. Imeio: chfalci@gmail.com.
}

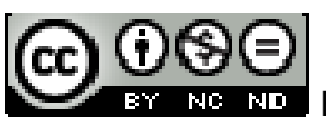

Texto Digital, Florianópolis, v. 8, n. 2, p. 148-173, jul./dez. 2012. ISSNe: 1807-9288 
momentos (VAN DJICK, 2007). A partir das poéticas de banco de dados, do uso de metadados e da facilidade de uso das estruturas de programação, o registro digital passa por novos conceitos de organização, classificação e navegação (MANOVICH, 2001, 2008; OLIVEIRA, s/d; RUPPEL 2009).

O crescimento de formas digitais de registro, entretanto, denota cuidados, como aponta Tim Fawns (2010), ao analisar a relação entre a memória episódica e memória semântica e as formas de mediação tecnológica da memória. Fawns argumenta que a facilidade de registrar momentos, tanto no que diz respeito à velocidade quanto à quantidade, já estaria gerando um engajamento mais superficial em relação às práticas de memória. Esse engajamento menos compromissado poderia levar a uma redução da importância da memória episódica, em favor da memória semântica. Ainda que esta possa ser considerada mais superficial, também pode ser vista como um modo importante de registro dos fatos. Fawns aponta para a necessidade de sermos mais seletivos e procurarmos um envolvimento mais profundo com os conteúdos que serão objetos de registro.

Uma das maneiras de ampliar e aprofundar a relação com objetos de memória pode estar relacionada ao uso dos metadados de forma poética, para além de pensá-los apenas como formas de organização eficiente dos registros. Eles podem ser criados e utilizados de modo a conectar mais fortemente acontecimentos cotidianos com aqueles capazes de provocar um envolvimento emocional intenso. Esse artigo não analisa a questão das memórias pessoais isoladamente, mas sim o entrelaçamento entre memórias comunicativas e memórias culturais, ou seja, memórias produzidas coletivamente. Se há cada vez mais suportes de produção de memória, é preciso compreender de que maneira tais suportes provocam o intercruzamento das memórias comunicativas com as memórias culturais e permitem o surgimento de memórias culturais em permanente estado de construção. Os projetos analisados nesse artigo parecem indicar que, para além de uma questão de organização ou de maior eficiência no registro dos fatos, as memórias mediadas tecnologicamente, com uso de 
metadados, não são formas de registro amplificadas, mas sim a criação de memórias culturais a partir de uma poética baseada em metadados. Para compreender melhor a relação entre memórias culturais e comunicativas, cabe entender o caráter coletivo de registro desses tipos de memórias. A pesquisa aqui apresentada faz parte de um projeto de pesquisa mais amplo, financiado pela FAPEMIG, e cujo objetivo final é produzir experimentos que testem a hipótese que ora se discute, sobre novas arquiteturas para memórias culturais em ambientes programáveis.

\section{Memórias coletivas, culturais e comunicativas}

Halbwachs afirma que nossas lembranças são coletivas e elas nos são lembradas pelos outros. E essa memória coletiva só permanece enquanto o grupo se mantém junto, coeso (HALBWACHS, 2006). Com base na concepção de Halbwachs, é possível perceber que a memória coletiva apresenta um caráter de transitoriedade, porque poderia ser desfeita quando o grupo social que a conserva também se desfizesse. Além disso, a memória coletiva de um grupo social envolve as memórias de todos os seus indivíduos. Como um acontecimento vivenciado por uma pessoa pode fazer parte de diversas redes vividas por essa pessoa, a memória desse acontecimento é sempre um momento transitório de percepção do evento e das próprias redes das quais o evento participa.

A memória de um grupo, entretanto, pode sobreviver para além da permanência desse grupo social conforme sua formação original. Através de processos narrativos de naturezas diversas as memórias atravessam gerações e funcionam como locais de contato e fricção entre passado, futuro e presente (TILL, 2008; ROWE; WERTSCH; KOSYAEVA, 2002). Obviamente, as narrativas sobre memórias interferem no modo como as memórias coletivas atravessam gerações (TSCHUGGNALL; WELZER, 2002; BROWN; MIDDLETOWN; LIGHTFOOT, 2001). Através de processos discursivos e não discursivos um grupo produz novas memórias coletivas sobre si mesmo, incessantemente. Como destaca van Dijck (2007) ao discutir as memórias mediadas na era digital, as memórias 
individuais e coletivas são formadas em conjunto, com os objetos da mídia funcionando como elementos que facilitam e produzem esses relacionamentos. Brockmeier (2010) ajuda a reafirmar essa visão, ao defender a ideia de que a memória é um fenômeno cujas materialidades e as nossas visões sobre esse mesmo fenômeno não podem ser separadas. Citando pesquisas na área de neurociência, van Dijck (2007) defende que a memória e a imaginação são fenômenos muito semelhantes, uma vez que ativam processos celulares e neurológicos semelhantes. As memórias são sempre forjadas novamente, quando são ativadas por algum acontecimento, o que revelaria uma alta flexibilidade em relação ao que está supostamente armazenado na mente. E dizemos aqui supostamente porque o trabalho de memória não compreende escavar a mente em busca dos fatos guardados. Cada narrativa de memória produz uma nova visão sobre um determinado fato vivido por uma pessoa.

Em relação aos modos narrativos associados às memórias, é possível destacar dois conceitos centrais ligados ao estudo da memória como fenômeno cultural: a memória cultural e a memória comunicativa. Assman (1995) define a memória cultural como todo conhecimento obtido através de práticas sociais repetidas ao longo do tempo, que funcionam como elemento que estrutura o comportamento e a experiência de vida de um grupo social. A memória cultural seria construída pela cristalização de ritos, eventos, acontecimentos, os quais poderiam ter seus significados transmitidos através do tempo. Para existir, esse tipo de memória solicitaria algum tipo de ordenamento e fixação temporal, o que comumente acontece quando essa memória se encontra registrada em suportes físicos, como a escrita em papel, a fotografia, as imagens em movimento etc. Os suportes físicos de registro da memória cultural pareceriam ser capazes de minimizar a velocidade de mutação das memórias coletivas, ao se dissociarem, aparentemente, da dinâmica do corpo social em que tais memórias foram produzidas. Essa premissa se mostra perigosa, uma vez que se baseia numa lógica tecnológica determinista e rígida, em que os objetos técnicos não seriam nada além de repositórios inertes dos acontecimentos. Leroi-Gourhan (1990) afirma que, com o surgimento dos textos impressos, os leitores se depararam não 
só com um enorme conjunto de memória coletiva, bem como foram confrontados com a impossibilidade de fixar completamente essa memória, uma vez que os suportes escritos permitiram a multiplicação incessante do registro dos fatos e acontecimentos de sua época. Featherstone (2000) argumenta que os suportes de memória transformam não somente o modo de produção dessas memórias, mas as próprias condições que definem o que se denomina cultura e como os grupos sociais compartilham essa cultura. Nessa mesma linha, Brockmeier (2002) indica uma mobilidade maior da memória cultural, uma vez que esse tipo de memória está diretamente associado aos contextos discursivos que a produzem. A memória surge então como um conceito relacional, sujeito às modificações que afetam as instâncias narrativas nas quais ela se manifesta. Essa abordagem aproxima a memória cultural da memória comunicativa.

Segundo Assman (1995), a memória comunicativa é baseada na comunicação cotidiana: ela seria caracterizada por um alto grau de não especialização, instabilidade temática e desorganização. $\mathrm{Na}$ visão do autor, ela seria demasiadamente instável para se configurar como uma cultura objetivada, e logo, como elemento capaz de identificar uma coletividade. Além disso, a principal limitação da memória comunicativa na estruturação da identidade de um grupo social seria seu horizonte temporal limitado, uma vez que o horizonte da memória comunicativa se modifica diretamente com o passar do tempo. É interessante notar, entretanto, que a institucionalização que caracteriza a memória cultural tem suas bases remontadas ao dia-a-dia, embora ela se distancie da mudança diária constante em função da sua lógica de objetivação cultural.

O uso de metadados pode fortalecer a conexão e o cruzamento entre memórias culturais e memórias comunicativas. Afinal, aplicar um conjunto específico de metadados a um grupo heterogêneo de informações pode revelar ligações mais fortes entre tais dados, e que não foram exploradas porque os dados foram capturados de maneiras e em momentos muito diversificados. Se as formas variadas de registro apresentam o perigo de enfraquecer a memória episódica, 
potencialmente elas também trazem consigo uma outra forma de encarar as memórias mediadas tecnicamente.

\section{Redes sociotécnicas, ambientes programáveis e metadados}

Longe de fixar uma memória, os suportes físicos multiplicam as camadas de memória coletiva, uma vez que as variadas formas de registro dos fatos apenas intensificam a noção de que a memória não deixa de ser reconstruída, mesmo nos suportes que deveriam fixá-la (BROCKMEIER, 2010). Se a fotografia utiliza o registro da luz para compor suas imagens, o cinema intensifica essa relação acrescentando o registro do tempo, do movimento. A imagem do vídeo produz uma fragmentação ainda mais radical, uma vez que se trata de uma composição eletrônica, baseada em uma varredura sobre os pontos em uma tela eletromagnética. No caso das interfaces digitais, tanto o tempo quanto o espaço tornam-se calculáveis, em função da lógica de funcionamento de uma mídia híbrida (MANOVICH, 2007). Couchot (2003), ao falar das imagens numéricas, as define como imagens-matriz, porque são produzidas através de cálculos matemáticos puros, podendo até mesmo existir sem nenhuma referência a qualquer objeto real. Essas imagens inauguram, assim, um tempo ucrônico ${ }^{1}$ e um espaço utópico.

As interfaces em que se procura criar um registro sobre os acontecimentos vão se organizar, progressivamente, em outras redes de memórias, como no caso de acontecimentos transmitidos por redes de televisão ao redor do mundo, para ficarmos com apenas um exemplo. As novas redes, por sua vez, produzem relacionamentos diferenciados entre os seus conteúdos, o que termina por modificar a percepção que cada um deles poderia produzir se estivesse registrado

\footnotetext{
${ }^{1}$ Tempo ucrônico é um conceito utilizado por Couchot que designa a abertura de várias camadas temporais, a partir da noção do tempo criado numericamente, pelo cálculo. É um tempo que se auto-engendra, sem fim ou começo, um tempo aberto à eventualidade.
} 
isoladamente. Além disso, os desenvolvimentos desses mesmos suportes (rádio, fotografia, celulares, televisão), em direção à possibilidade de registro do tempo "real" dos acontecimentos, produzem também modificações sobre a percepção do real, o que consequentemente provoca uma reavaliação sobre a relação entre tais dispositivos e sua capacidade de produzir memória. Se nessa primeira etapa de mediatização da memória (HOSKINS, 2009), a lógica ainda é a de acúmulo de arquivos e transmissão unidirecional, com as interfaces digitais, os modos de registro permitem decompor os elementos registrados, que podem então ser manipulados indefinidamente. Hoskins caracteriza a mediação digital como uma segunda fase de mediatização da memória, caracterizada por uma intensa conectividade entre dados de natureza diversa. Os dados em formato digital são apresentados de forma modular, o que permite a simulação de todas as temporalidades, bem como a ideia de que não há um espaço prévio ao espaço digital, ele aparece enquanto espaço porque são as interações sociotécnicas que o produzem. Como afirma van Dijck (2007), as ferramentas computacionais penetram de tal maneira nos nossos processos de memória que tornam difícil distinguir os limites entre os objetos e a memória.

Lev Manovich (2001) afirma que as interfaces digitais criam uma transcodificação cultural, ao associarem elementos que são próprios de uma cultura computacional com elementos que seriam mais diretamente ligados à cultura humana. Os algoritmos são utilizados para produzir informação e deixam suas marcas no modo como as informações circulam nas redes sociotécnicas (Hertz, 2009). As marcas aqui indicadas podem se configurar como metadados que, ao serem manipulados, produziriam uma memória dos usos de cada tipo de registro. É possível ver, em projetos como geoplay.info, de Rafael Marchetti, como o próprio dispositivo utilizado para agrupar as memórias convoca a olhar para a memória das interfaces. Essas, por sua vez, tornam-se cada vez mais adaptativas, mesclando a lógica de uma agência humana à lógica de uma agência maquínica (FISCHER; GIACCARDI, 2008). Esse modo de existência influencia e é influenciado também pela forma de funcionamento das redes que tais interfaces criam. 
Uma rede pode ser definida como "uma estrutura de interconexão instável, composta de elementos em interação, e cuja variabilidade obedece a alguma regra de funcionamento" (MUSSO, 2004, p. 31).

As regras desse ambiente, no entanto, são modeláveis, o que permite conectá-lo a ideia de ambientes programáveis. Pode-se afirmar, então, que a rede é sempre temporária, porque só existe quando está em ação, quando é ativada por algum dos elementos que a compõem (SERRES, 1990). Uma rede é também sempre sociotécnica, funcionando numa lógica de continuidade entre esses dois termos. No caso de ambientes programáveis, a continuidade entre sujeito e objeto e a indistinguibilidade dos mesmos surge, cada vez mais, como uma marca seminal. Dentro de tais ambientes, as memórias culturais, por consequência, são revestidas com elementos não tradicionais, e mostram diversas camadas temporais em conjunto, sem que haja necessariamente uma sobreposição entre elas. A memória não se encontraria mais no registro de cada instante, mas justamente na conjugação entre fatos registrados, fatos em processo de registro, e fatos passíveis de acontecerem, que surgiriam num tempo ucrônico, num tempo possível, e não mais num tempo já dado, já narrado (COUCHOT, 2003).

\section{Memórias culturais em construção: novas formas de memórias com uso de metadados}

Andrew Hoskins (2009) utiliza o termo "on-the-fly", para caracterizar a memória distribuída em redes digitais. Em função de se encontrar "distribuída" digitalmente, esse tipo de memória é ativamente construída e reconstruída o tempo todo, ou seja, enquanto está sendo formulada como registro de um acontecimento. Isso se deveria ao alcance e à lógica das interfaces baseadas em mídias móveis e o modo como tais mídias captam incessantemente o cotidiano (SOUZA E SILVA, 2004). Nesses ambientes, a memória cultural se aproxima cada vez mais do momento de acontecimento dos eventos, numa temporalidade ucrônica, provocando um entrecruzamento com as memórias comunicativas. Nesse 
sentido, os mecanismos sociotécnicos atuais de registro da memória produzem modificações instantâneas dos fatos registrados, porque os colocam em novas redes de memória a todo o momento. Como afirma Hoskins (2009), à medida que os recursos digitais de produção de memória se tornam mais acessíveis aos indivíduos comuns, essas pessoas passam a criar "locais" de memória baseados nas diversas redes sociotécnicas que surgem a todo o momento, como Youtube, Flickr, Facebook, entre outras. Estes sites, por sua vez, contribuem para borrar, senão para transcender as noções de público e privado, de particular e coletivo. Além disso, o próprio caráter de fluidez dos ambientes programáveis contribui para que artistas e pesquisadores produzam experiências de rearticulação dos conteúdos pessoais e coletivos espalhados nas redes, forçando os indivíduos que utilizam essas redes a reavaliarem as estruturas digitais de mediação da memória. Os metadados funcionam como responsáveis, nesses casos, como articuladores, como ligações entre conjuntos semânticos de memória, ainda que tais conjuntos não sejam construídos por um grupo social definido a priori. Como afirma Arthur (2009), quando discute os conceitos de biografias digitais, as maneiras como nos lembramos das coisas cotidianas são transformadas por novas tecnologias de memória. Numa lógica de retroalimentação, os conteúdos capazes de se tornarem memórias mudam, e contribuem também para alterar as tecnologias que utilizamos para registrá-las. Para van Dijck (2007), o potencial multimodal dos objetos digitalizados tem a capacidade de redefinir os modos sensoriais que utilizamos para capturar e registrar as memórias. As memórias mediadas estão em constante estado de transição, tanto em suas formas materiais quanto conceituais. Surgem, então, novas formas de memória, o que denomino memórias culturais em permanente estado de construção. Em busca desse tipo de memórias, serão analisados projetos cujo funcionamento exemplifica o que acontece quando a memória comunicativa aparece já como memória cultural, e como essa última não perde o seu status quando aparece em rede, mas ganha outro modo de existência.

\section{We feel fine}


O projeto We feel fine (http://wefeelfine.org) se destina a explorar as emoções humanas numa escala global, segundo seus criadores. O projeto está no ar desde 2005, e sua lógica de funcionamento, de maneira resumida, é a seguinte: a cada dez minutos, um sistema faz uma busca, em blogs listados em fontes como LiveJournal, MSN Spaces, MySpace, Blogger, Flickr, Technorati, Feedster, Ice Rocket e Google, por postagens que tenham as frases I fell ou I am feeling. Interessante perceber que as fontes são enormes organizadores de blogs, o que sugere que os dados organizados constituem uma quantidade enorme de informações que misturam o privado e o público. São relatos pessoais incrustados em objetos culturais (blogs) que criam sentido tanto para as experiências particulares quanto atribuem novas percepções histórias e políticas para eventos cuja abrangência é coletiva (VAN DIJCK, 2007).

A partir da localização das frases, o sistema as analisa e verifica se elas contêm alguma palavra de uma base de dados com 5.000 "sentimentos" pré-identificados. Quando uma correspondência acontece, o post que representa o sentimento de uma pessoa surge dentro da interface de visualização, como um círculo colorido. Se uma imagem estiver junto com o post, o círculo se transforma em um retângulo colorido. Cada círculo ou retângulo, ao ser acessado, permite ver a frase completa ou a imagem com a frase que está associada a ela. Além disso, o sistema recupera ainda informações específicas dos usuários que fizeram as postagens: idade, gênero e localização geográfica. Nessa forma de busca, acontece já uma apropriação do conteúdo de maneira que vai além da simples recuperação de informação. As variáveis de identificação básica são resgatadas para produzir experiências estéticas específicas. Outra informação que é salva diz respeito às condições meteorológicas do local físico informado no profile do usuário, no momento em que a informação é escrita. Esse dado é coletado em sites de informação meteorológica e comparado a cada um dos blogs pesquisados pelo projeto, configurando uma possibilidade diversa de utilização de metadados para além da classificação de informações. Através desse mecanismo, o interagente é provocado a pensar qual é a relação entre os posts em cada blog e os dias ensolarados, por exemplo. Não que a correlação seja feita 
diretamente, mas são essas aberturas que nos levam a dizer que projetos como We feel fine utilizam de forma poética os metadados. Há aqui aquilo que Manovich (2001) discute quando fala das várias interfaces para um mesmo conjunto de informações, de modo que o que vemos então na interface, explicitados, não são os dados puros, mas as ligações entre eles. Essas, por sua vez, ecoam a conexão entre memória e imaginação, pois são ligações que conferem uma outra visão aos fatos armazenados, como que a dizer que tais "lugares" de memória se deslocam todo o tempo, de acordo com o modo como os acessamos.

A interface do projeto é auto-organizável, e as características de cada partícula indicam a natureza dos sentimentos que elas carregam: cor, forma, tamanho e opacidade são elementos de conteúdo, constituindo uma visualização do modo como os algoritmos leem e interpretam o banco de dados. As partículas ficam girando na tela até que sejam chamadas a se organizar a partir de algum dos seis movimentos criados como algoritmos de organização da base de dados: loucura, murmúrios, montagem, mobs, métricas e mounds. É uma organização um tanto quanto peculiar, porque mistura tipos de emoções com dados estatísticos, aparentemente. E embora sejam conjuntos de informações que possuem níveis semânticos diferenciados, é justamente a forma de funcionamento em metadados que provoca o usuário a repensar as suas próprias memórias e o lugar de cada uma delas nas narrativas pessoais e coletivas.

As formas de visualização em We feel fine são extremamente variadas, estão organizadas em movimentos que o interagente escolhe, criando então um tipo diferente de memória a partir de um conjunto comum de informações. Quando se seleciona Madness, o primeiro movimento, as partículas ficam se movimentando de forma aleatória pela tela. $O$ acaso irrompe nessa organização, e reforça a ideia de que memórias pessoais, associadas a sentimentos, não estão facilmente agrupadas em conjuntos bem delimitados. É o movimento na interface que irá produzir configurações semânticas para os sentimentos. Novamente, a memória 
será construída ativamente, através de ações numa interface caótica, em que as narrativas ainda não estão prontas.

O segundo movimento, que se chama Murmurs, apresenta um ambiente mais estruturado, em contraste com o ambiente Madness. Nesse movimento, as partículas se organizam no alto da tela, num primeiro momento. Gradualmente, elas começam a se desprender do teto e vão descendo pela tela, em ordem cronológica inversa ao momento em que foram postadas. Aparecem, primeiro, aquelas frases que acabaram de ser postadas e progressivamente podem ser vistas frases que foram postadas há mais tempo. Essa visualização permite experimentar mais claramente a variedade de sentimentos sendo expressos, assim como ver a distância ou a similaridade, ao longo do tempo, entre sentimentos postados, por indivíduos que talvez não tenham nenhum contato entre si. Há ainda outra característica dessa forma narrativa: as frases são formadas letra a letra, como estivessem sendo digitadas no momento mesmo em que se desprendem do alto da tela. Quando surgem novas sentenças, aquelas mais antigas desaparecem gradualmente, o que reforça um dos conceitos importantes para esse artigo: todo uso provoca uma memória. Metaforicamente, a substituição das sentenças indica que as histórias não contadas tendem a deixar de fazer parte da memória cultural. Assim, a interface reforça, a todo momento, o par lembrança-esquecimento, e a própria instabilidade do digital como uma marca da impossibilidade desse tipo de "materialidade" guardar todas as memórias produzidas. Ao analisar o conceito de estruturas cross-sited, Ruppel (2009) afirma que tais tipos de narrativas funcionam como recursos metalinguísticos sobre 0 próprio meio em uso. A interface de We feel fine desafia o interagente a olhar para os blogs não mais somente como milhares de narrativas desconexas, mas sim como narrativas à espera de relacionamento, nesse caso, relações possibilitadas pelo recurso dos metadados. Através do projeto os blogs podem ser vistos como uma memória pessoal cultural, em constante construção, já que as relações, em We feel fine, são reconstruídas pelo recurso de composição da interface incessantemente (VAN DIJCK, 2007). 
No terceiro movimento ou forma de visualização, intitulado Montage, é possível ver frases que contém imagens associadas aos posts e, assim, perceber de outra maneira como se organizam os sentimentos de uma dada população. Surge então uma estrutura visual das emoções, e talvez aqui fique mais fácil também discutir se as imagens têm algo em comum. Cabe nos perguntarmos se elas podem funcionar como uma memória cultural de uma dada população, ainda que essa população não se configure como um grupo social articulado em torno de preservar suas memórias numa ordem altamente estruturada. Nesse caso, parece-nos que a memória cultural é criada pela interface, ou ao menos, é proposta pela organização que a interface proporciona. Entretanto, não se trata mais do conceito de memória cultural de Assman (1995), mas de uma estrutura híbrida, em que estão entrelaçadas as lógicas da memória comunicativa e da memória cultural.

O quarto movimento, Mobs, é dividido em cinco pequenos movimentos, que permitem visualizações baseadas em algumas buscas padronizadas que são propostas no site. O primeiro subitem dessa categoria se chama Feeling e apresenta os sentimentos mais comuns para uma dada população escolhida. Nesse movimento as partículas se auto-organizam em linhas que apresentam sentimentos compartilhados. As linhas são organizadas a partir do número de partículas relativas a um determinado sentimento, e dentro de cada linha as partículas são organizadas a partir do comprimento de cada sentença. Qualquer partícula, ao ser escolhida com um clique, dá acesso à frase a que está relacionada. O segundo subitem organiza as emoções a partir dos gêneros, 0 terceiro pela idade, o quarto pelo tempo e o quinto pela localização.

O quinto movimento, Metrics, mostra os sentimentos mais salientes em relação a uma determinada população. A diferença entre Mobs e Metrics diz respeito justamente a essa delimitação a um conjunto de dados específicos. $E$ isso indica também como o projeto "brinca" com vários modos de visualização e produção de memórias, ao permitir que as camadas temporais sejam experimentadas instantaneamente dentro do projeto. Dentro da seção Gallery/Montage é possível 
salvar imagens de sentimentos encontrados dentro do projeto, além de enviar esses sentimentos via email para alguém, juntamente com uma mensagem que pode ser escrita no email. Surge, então, uma outra maneira de compartilhar as redes de memória produzidas pelo projeto.

As formas variadas de exibir os sentimentos enfatizam o que defendo nesse artigo: os ambientes programáveis parecem mais aptos a funcionarem como memórias em movimento do que como repositórios cujo objetivo primordial é guardar o tempo, torná-lo impenetrável e, com isso, esgotar a própria dinamicidade das narrativas de memórias. Por essa razão, entendo que Tim Fawns tenha razão no seu temor quanto a sermos menos seletivos porque podemos agora registrar todo e qualquer fato, sem nos demorarmos a vivenciá-lo. Mas entendo também que essa preocupação talvez esteja olhando para as interfaces digitais somente como mecânicas de registros isolados entre si. Dispor tais experiências em rede pode produzir outro tipo de seletividade em relação às memórias digitais compartilhadas. De qualquer maneira, a minha preocupação ao enfatizar a poética dos metadados é similar ao que compreendo do alerta de Fawns (2010): evitar que o uso das interfaces digitais se torne uma ação trivial, comandada somente pela parte funcional dos códigos de programação. A perspectiva que os artistas criadores do projeto We feel fine abrem aponta justamente para uma necessidade de utilizarmos as informações em rede não como simples dados impessoais, mas como objetos poéticos capazes de estruturar memórias insuspeitas, capazes de dialogarem entre si em função da linguagem de programação das API's do projeto, por exemplo.

\section{Between Blinks and Buttons}

O projeto Between Blinks and Buttons foi realizado em Processing, utiliza mídias móveis e a base de dados do Flickr. Segundo a documentação do projeto, o trabalho procura criar narrativas que conectam a memória de uma pessoa com um momento vivenciado por um estranho e que parece coincidir temporalmente com essa memória. O projeto utiliza explicitamente os dados anexados às fotos 
digitais, as EXIF-tags e as transforma em informações que podem ser ligadas às memórias presentes nas fotos.

A parte denominada Blinks é uma instalação em que fotos são projetadas numa superfície, de maneira randômica, como se estivessem jogadas em cima da mesa. Um objeto similar a um prisma é utilizado pelo usuário para se mover pelas imagens projetadas. Quando esse objeto é posicionado sobre uma foto por alguns instantes, raios de luz projetam outras fotos nas paredes da caixa em que as fotos estão "guardadas". As imagens projetadas nos lados da caixa são imagens buscadas no Flickr, cuja data e hora são as mesmas daquela sobre a qual o prisma está posicionado. Se o prisma é rotacionado, as imagens se movem nos lados da caixa, e se tornam mais largas ou mais finas, de acordo com a relação entre o fuso horário das imagens. Os quatro lados da caixa estão divididos de acordo com as vinte e quatro time zones do sistema de fuso horário baseado no Greenwich Mean Time. Quando a foto é projetada num lado da caixa que corresponde ao fuso horário do local em que ela foi feita, essa imagem aparece mais larga, como se estivéssemos mais próximos do local em que aquela lembrança aconteceu. O projeto cria uma refração temporal, mostrando várias imagens de um mesmo tempo, mas de locais diferentes, num mesmo local. Surgem, assim, várias camadas de memória relacionadas a um mesmo momento temporal, e associadas a um conjunto de metadados que serve não só para identificar as imagens, mas para produzir narrativas de memória e conexões entre as mesmas. Como o banco de dados do Flickr se mantém constantemente em atualização, e as tags que identificam as fotos são também passíveis de modificação, a memória que o projeto constrói é sempre volátil, o que não significa considerá-la automaticamente como uma aproximação superficial dos eventos. Antes, o que a instalação revela é a capacidade dos metadados para criar novas poéticas de memória a partir da multiplicidade de dados contidos nas redes sociotécnicas. É nesse sentido que se sugere a poética dos metadados como uma possível saída para a elaboração de memórias que não se transformem em simples aglomerados de informações, ou em memórias semânticas que não implicam emocionalmente aqueles que as registraram. A 
discussão que projetos como esse suscitam tem, potencialmente, a força de fazer com que usuários de celulares, câmeras digitais e outros dispositivos de registro de memória repensem a produção ininterrupta de imagens, assim como a quantidade de informações que cada imagem carrega e a maneira como elas podem ser interligadas. Parece-nos urgente fazer com que tais projetos habitem mais as redes, sejam mais divulgados e passem a ser utilizados por um número maior de pessoas. A proliferação de tais interfaces pode contribuir para aproximar a imaginação, a memória, a tecnologia e a arte dos processos cotidianos de produção de informações.

Na parte denominada Buttons, a ideia é aproveitar a lógica de que toda foto produz uma memória, e conecta as pessoas a momentos que já viveram e pode também vir a se tornar uma memória cultural, que sobrevive para além das conexões particulares que cada um produz sobre aquela foto. A partir do momento em que se dispara o botão de captura, a câmera, que é um celular conectado a um servidor rodando um script de busca, inicia a busca, no Flickr, por imagens que possuem as mesmas referências de hora e data do momento de disparo do botão. Assim que uma imagem é postada no Flickr com os mesmos parâmetros, ela pode ser encontrada pelo mecanismo de busca do celular e é exibida na tela do aparelho. A foto que a pessoa que utilizou o celular vê é uma foto do Flickr, e não a "sua" foto, que serve como parâmetro de busca. Postar as fotos num banco de dados como o Flickr também funciona, atualmente, como parte da experiência de fazer uma foto.

O projeto considera a câmera fotográfica como um objeto em rede. O criador do projeto transformou a câmera num instrumento que captura o momento experimentado pela pessoa que a utiliza, e separa esse objeto do sujeito que 0 produziu, no momento da captura. A câmera não possui partes óticas tradicionais, como numa câmera digital ou analógica. Os elementos registrados pela câmera são informações de controle, que podem servir ou não para a organização sentimental e particular das imagens, mas que dentro do projeto se transformam em elementos de conexão com outras imagens e com outras pessoas. Há dentro 
do projeto a produção de uma subjetividade que mistura memórias, aparatos e agentes humanos e maquínicos.

Como os parâmetros de data e hora em que a imagem foi feita podem ser alterados no Flickr, essas informações produzem novas redes de contato, redes de memória. Ao alterar a data e hora de uma imagem o que uma pessoa está produzindo dentro do Flickr é uma nova rede de memória, se considerarmos a lógica de ação do projeto Between Blinks and Buttons. Essa possibilidade reforça a visão de Santos (2001) quando afirma, juntamente com Derrida e Benjamim, que a memória não tem um objeto em si mesma que deveria ser lembrado. Por isso, ela, memória, não deveria ser buscada ou reconhecida nos objetos, mas nas relações entre os mesmos. Fica patente a qualidade dialógica da memória, (BROCKEMEIER, 2010), o que corrobora a importância do processo de construção de memórias, e não somente um olhar para os arquivos como os únicos lugares de memória. A partir dessa constatação, Brockemeier defende que a crise da memória não deve ser considerada como uma diminuição das capacidades humanas para lembrar ou esquecer de algo, mas como uma crise da noção de arquivo e dos limites desse modelo para dar conta de representar a plasticidade da memória. Ou seja, o que se critica então seria a lógica de como arquivar e, talvez, a própria lógica de arquivar mesmo, de arquivar memórias. $\mathrm{O}$ projeto Between Blinks and Buttons tensiona justamente esse ponto, a partir de dois movimentos: na parte denominada Buttons, ao impedir o acesso à foto que a câmera registra, e entregar ao usuário da câmera uma outra imagem, ele desfaz a noção tradicional de arquivo e sugere que esse lugar deva ser pensado como uma ação de criação de memórias culturais, coletivas ou pessoais. Afinal, os atuais relatos de acontecimentos, consolidados pelas estruturas midiáticas não se constituem, todos eles, em redes intrincadas de relações entre imagens produzidas por vários aparelhos de captura e registro? O projeto Between Blinks and Buttons entrega essa possibilidade a pessoas comuns, e nos força a considerarmos cada um dos atos realizados com um aparato digital em rede como algo capaz de constituir as memórias do mundo em que vivemos. 


\section{Geoplay.info}

A obra de Rafael Marchetti é uma aplicação para web que mescla o serviço de rotas urbanas do Google Maps com fotografias georreferenciadas publicadas por usuários do site Panoramio na internet. Segundo o site do projeto a obra equaciona (trajetos+percursos urbanos (artificiais*rotas fictícias) ${ }^{*}$ mídias[recicladas-re-utilizadas]). Nessa "fórmula" matemática já é possível perceber uma mistura de várias camadas de memória: a memória baseada na subjetividade dos objetos culturais programáveis, mesclada com uma parcela das experiências de cada usuário do site Panoramio.

A interface de geoplay.info apresenta ao usuário, em sua tela inicial, duas solicitações: o endereço inicial do trajeto e o endereço final. Após digitar esses endereços, o projeto compara as entradas com aquelas reconhecíveis pelo serviço de rotas do Google Maps e sugere correções, considerando a lógica de mapeamento utilizada pelo sistema do Google. Essa interferência confirma o que foi dito acima: há uma primeira camada de memória que diz respeito ao modo como o serviço do Google Maps compreende o espaço geográfico. Somos provocados, desde o início, a considerar que o trajeto exibido é uma construção imaginária, mesmo que se possa dizer que ela é baseada em parâmetros cartográficos ou de programação. O que utilizamos ao manusear o Google Maps é um conjunto de metadados organizados numa narrativa definida pelo modo de funcionamento da API (Application Programming Interface) criada pela Google.

Após escolher os endereços e observar os ajustes realizados pelo serviço do Google Maps, o usuário solicita que o projeto geoplay.info comece a traçar o trajeto entre os dois pontos digitados. Na construção desse caminho a interface de geoplay.info detalha cada ponto da rota, indicando que a elaboração daquele espaço está acontecendo no momento da ação solicitada pelo usuário. Cada ponto é acompanhado da inscrição das fotos associadas àquele local, textualmente. As fotos são identificadas pela latitude e longitude ou pelo nome dos usuários que postaram as fotos, quando essa informação está disponível no 
Panoramio. Devido ao grande número de imagens na plataforma, cada ponto da rota pode conter várias fotos. O acúmulo de imagens em cada ponto também pode ser visualizado no Panoramio, mas quando é associado a um trajeto, a um percurso que o usuário deseja "experimentar", como no caso de geoplay.info, o que se sugere é um olhar diferenciado sobre a narrativa do espaço. O projeto não apresenta simples percursos, mas o modo como eles foram experimentados e como são registrados como objetos de memórias mediados, por cada usuário. As rotas criadas pela interface tornam-se um "objeto" de memória que confere sentido narrativo às informações ainda não interligadas, provenientes de diferentes fontes. O que é o arquivo de memória em geoplay.info? E como entender as fotos em Panoramio, ou mesmo as rotas do Google Maps, uma vez que elas podem ser reutilizadas para gerar memórias que só existem em razão da articulação dessas imagens com conjuntos de metadados, códigos de programação e interfaces maleáveis? Estamos diante de novas memórias, ou diante de interfaces capazes de mostrar qualidades da memória que antes só seriam creditadas à imaginação, ou a experiências impossíveis de serem mostradas? Não se trata de interfaces capazes de arquivar essas experiências, como se elas pudessem ser revividas depois em função dos arquivos digitais, mas simplesmente de enaltecer que a memória se faz pelas conexões, pelo diálogo, pelas relações entre os acontecimentos e as formas como fazemos esses acontecimentos emergirem em contextos variados. É a partir desses elementos que pretendemos esboçar algumas conclusões sobre a relação entre memórias e o uso de metadados em ambientes programáveis.

\section{Memórias culturais em ambientes programáveis: algumas conclusões}

As obras descritas permitem indicar alguns pontos-chave para caracterizar as memórias culturais em estado de construção, a partir de um uso poético dos metadados.

O primeiro elemento relaciona-se ao modo como a dinâmica das redes perpassa a construção dos conteúdos produzidos pelos grupos sociais nesses ambientes. 
No caso de We feel fine, não há grupos sociais articulados previamente para produzir os sentimentos. A forma como a obra propõe a visualização das frases é que permite perceber o surgimento de uma memória cultural ainda não completamente ritualizada, produzida de forma descentralizada, sem hierarquia, mas que poderia ser considerada como cultural em função do modo como o projeto agrega as informações dispersas em blogs. Há aqui, ao mesmo tempo, a memória comunicativa, presente em cada blog, e a memória cultural em constante construção, uma vez que o sistema de We feel fine continua a construir novas memórias, de dez em dez minutos. A interface do projeto se associa à própria imprevisibilidade e ao pluralismo da rede para nos provocar a pensar em uma memória que é, simultaneamente, registro e criação de relações entre uma produção coletiva não-hierarquizada. Ao consultar We feel fine e utilizar os seus vários modos de visualização, o usuário produz memórias culturais derivadas de uma poética que mescla bancos de dados e programação, que cria arquiteturas de memórias baseadas em metadados, ou o que pode ser descrito como "metadata memories".

segundo elemento-chave se relaciona às interfaces fluidas utilizadas nos projetos, e o modo como elas participam da produção de conteúdo. Ao permitir o registro cotidiano permanente de fatos, a utilização dos celulares cria uma memória cultural que é atemporal num novo sentido, porque é constantemente atualizável. Os celulares podem intensificar a percepção de que a memória cultural está sempre em constante equilíbrio, entre o acontecimento e a estabilização dos significados. Esse parece ser o caso de Between Blinks and Buttons, em que os metadados produzidos pela câmera, que podem servir ou não para a organização sentimental e particular das imagens, se transformam em elementos de conexão com outras imagens e com outras pessoas, a partir da busca no Flickr. Bancos de dados como Flickr são conjuntos de fragmentos visuais de vidas particulares. Mas podem também se tornar grandes conjuntos de memória, dependendo da forma como são organizados, ou como colocam em contato várias pessoas ao redor do mundo. $O$ projeto segue essa lógica de 
associar um banco de dados extenso e "impessoal" com experiências particulares e momentâneas.

O terceiro elemento que caracterizaria as memórias culturais em rede baseia-se na lógica dos metadados. Nos dois projetos descritos, o que se vê são memórias que mesclam informações cotidianas com metadados capturados de informações tornadas públicas pelos seus próprios criadores. Assim, a memória cultural aí construída não termina nunca de se fazer, porque os participantes da rede podem sempre alterar os seus metadados, e estão, cotidianamente, postando novas informações na rede, sem necessariamente levarem em conta que elas podem ser agrupadas a partir de parâmetros comuns. Isso torna necessário repensar o próprio termo memória cultural como algo que deveria manter certo caráter de imutabilidade física ao longo de um longo período de tempo.

Em relação à sugestão final do texto de Fawns (2010), sobre ser necessário redescobrir o valor dos artefatos de memória através de processos mais seletivos de captura, armazenamento e compartilhamento dessas informações, entendo que uma poética dos metadados abre dois caminhos que podem servir não como respostas, mas como sugestões de diálogo com as observações de Fawns. De um lado, a proliferação de projetos como os aqui analisados e sua consequente penetração como objetos de memória cultural pessoal ou coletiva talvez conduza a uma produção de memórias pensadas para se encaixar dentro de redes sociotécnicas de memória que, embora pareçam fluidas, seriam apenas uma reificação de esquemas impessoais e quase estáticos, portanto, mais próximos das memórias semânticas. Grandes bancos de dados em rede como Flickr, Youtube e outros levam os interagentes a criar tags ou metadados que conectam conteúdos conflitantes dentro de um mesmo conjunto de memórias, sem que isso seja feito para provocar um estranhamento deliberado ou algum tipo de experiência estética ou de crítica sobre esses mesmos bancos de dados. Há, dessa maneira, uma adequação ao modo de armazenar as informações, o que pode realmente transformar memórias episódicas em memórias que se tornam cada vez mais semânticas. Mesmo projetos como aqueles analisados aqui são 
capazes de criar também formas institucionalizadas de organização, a partir da poética dos metadados. Afinal, as regras de funcionamento de um projeto como We feel fine, por exemplo, podem acabar sendo utilizadas como uma maneira de criar posts que, fatalmente, serão agrupados ao conjunto de outras memórias sentimentais que já estão presentes ali. Assim, o projeto terminaria por suscitar a criação forçada de objetos de memória que caberiam dentro das condições estipuladas pelo programa. Não haveria, considerando o exposto, quase nenhuma diferença entre movimentos como esse e aqueles que procuram institucionalizar certas práticas, ritos ou monumentos para que estes passem a fazer parte de uma determinada memória cultural. O risco maior, no caso de blogs, é que talvez experiências muito pessoais terminem por se tornar experiências esvaziadas, já que serão selecionadas para se encaixar em parâmetros impessoais ou já programados, o que é diferente da criação de monumentos ou práticas destinadas já de princípio a fazerem parte de uma memória cultural com horizontes de duração mais longos.

Por outro lado, o uso de metadados de maneira poética instiga os usuários de ambientes programáveis a considerar mais seriamente todos os processos de seleção, armazenamento e compartilhamento que envolvem, atualmente, a produção de memórias digitais. É preciso, então, trabalhar com os metadados não apenas como informações técnicas e impessoais sobre o modo de captura ou organização de uma determinada imagem, mas conferir, a esse tipo de dados valores estéticos, simbólicos e pessoais que possam ser compartilhados dentro de redes mais amplas de memória cultural pessoal. Trata-se, num primeiro momento, de compreender o processo de seleção dos objetos para além do contato inicial com os artefatos de memória, o que não significa descuidar de envolvimentos mais intensos com as experiências cotidianas, em função da possibilidade fácil de registro das mesmas. Narrativas de memória em ambientes programáveis não podem ser compreendidas apenas pelo viés do acúmulo de imagens, vídeos, textos, sons permitidos pela proliferação de dispositivos digitais. Não defendo aqui uma substituição das experiências ao vivo pelo registro digital das mesmas e o compartilhamento em redes sociotécnicas, mas sim a 
necessidade de um olhar mais amplo sobre os diversos elementos envolvidos quando se decide criar uma memória pessoal sobre qualquer acontecimento. Para tanto, entendo que projetos como geoplay.info apresentam uma visada crítica a respeito da apropriação das memórias que já é realizada por sites, instituições e empresas que pretendem fornecer acesso mais rápido e eficiente às informações. A poética presente em geoplay.info está baseada no ato de transformar endereços funcionais (utilizados pelo sistema de rotas do Google Maps) em locais particulares, utilizando um repositório de imagens, o Panoramio, que não foi criado com esse intuito, inicialmente. Olhar para as diversas fotos de um mesmo endereço, à medida que a rota é criada, se ainda não pode ser considerado um ato de criação de memórias episódicas, faz ao menos repensar se não devemos ressignificar a experiência cotidiana ordinária, uma vez que ela agora pode se integrar a conjuntos de memória bastante diversificados. A conjugação de metadados de fontes diferentes, cujo objetivo primeiro é tornar funcional e eficiente a travessia de um lugar a outro, pode gerar não só novos percursos, mas uma consciência diferente sobre 0 ato de atravessar esses espaços e o modo como os atravessamos. Se entendermos esse modo como uma narrativa de memória, e os metadados como elementos narrativos, o que se sugere é a necessidade de agregar à memória conjuntos cada vez mais híbridos de experiências, em que se mesclam estados emocionais, especificações técnicas das interfaces de registro, condições ambientais, interfaces de compartilhamento de dados, entre outros elementos.

Como Veronesi \& Gemeinboeck (2009) destacam, as tecnologias móveis produzem uma re-incorporação da memória nas atividades cotidianas. As interfaces móveis, associadas à lógica das redes e ao contexto físico em que as informações são experimentadas, permitem que diferentes temporalidades coexistam em um mesmo ambiente, criado pelo uso cotidiano. Esse fato demonstra que as memórias culturais em permanente construção enfatizam a importância das ações diárias de produção de informação, sejam elas em rede ou em locais físicos (SOUZA E SILVA, 2004). 
Os ambientes programáveis, associados a tecnologias móveis de produção e disponibilização de informação, sugerem a necessidade de um olhar mais cuidadoso sobre o modo como já estão sendo construídas as memórias do futuro, e como tais memórias podem ser mais ou menos voláteis, em função da intensidade do uso que delas fizermos. Os projetos analisados permitem perceber como as interações em rede criam, efetivamente, uma nova arquitetura para as memórias. Ou dito de maneira melhor, uma arquitetura com e através das memórias, espaços de memória instáveis, programáveis e cujo modo de existência talvez possa ser descrito em uma frase, que deixo aqui a título de conclusão temporária: todo uso provoca uma memória.

\section{METADATA AND ARCHITECTURES OF MEMORY IN PROGRAMMABLE ENVIRONMENTS}

ABSTRACT: The purpose of this article is to discuss how the creation of collective memories in programmable environments, and with the use of metadata, results in the intercrossing of communicative memories with cultural memories and allows for the emergence of memory architecture, here denominated cultural memory in a permanent state of construction. The analysed projects seem indicate that memories technologically mediated, with metadata, aren't just amplified recording forms, but present themselves as a production of cultural memories based in a metadata poetics. To understand the relation between cultural and communicative memories, this article presents and discuss issues relating to the collective character of these type of memories. The research presented here is a part of a bigger project, funded by FAPEMIG. The main goal is to produce experiments that investigate how the programmable environments produce cultural memories.

KEYWORDS: Cultural memories. Communicative memories. Programmable environments. Metadata.

\section{Referências}

ASSMAN, Jan. Collective memory and cultural identity. In: New German Critique, n. 69. 1995. p. 125-133.

BROCKMEIER, Jens. Remembering and forgetting: narrative as cultural memory. In: Culture \& Psychology, vol. 8, n.1. 2002. p.15-43.

BROCKMEIER, Jens. After the archive: remapping memory. In: Culture \& Psychology, vol. 16, n. 1. 2010. p. 5-35. 
BROWN, S.; MIDDLETON, D.; LIGHTFOOT, G. Performing the past in electronic archives: interdependencies in the discursive and non-discursive ordering of institutional remembering. In: Culture and Psychology, vol. 7, n. 2, 2011. p. 123144.

COUCHOT, Edmond. A tecnologia na arte: da fotografia à realidade virtual. Porto Alegre: UFRGS, 2003.

FAWNS, Tim. Blended memory: the changing balance of technologically-mediated semantic and episodic memory. In: WILSON, P; MCENTAGGART, P. (Org.) Navigating landscapes of mediated memory. Oxford: Inter-disciplinary Press, 2011. p. 121-132.

FEATHERSTONE, Mike. Archiving cultures. In: British Journal of Sociology, vol. 51, n. 1. 2000. p. 161-184.

FISCHER, G.; GIACCARDI, E. Creativity and evolution: a metadesign perspective. In: Digital Creativity, vol. 19, n. 19. 2008. p. 19-32.

HALBWACHS, Maurice. A memória coletiva. São Paulo: Centauro, 2006.

HERTZ, Paul. Art, code and the engine of change. In: Art Journal, vol. 68, n. 1. 2009. p. 59-75.

HOSKINS, Andrew. The digital distribution of memory. 2009. Disponível em: $<$ http://www.inter-disciplinary.net/wp-content/uploads/2009/03/hoskins-paper.pdf $>$. Acesso em: 23 jan. 2010.

HOSKINS, Andrew. The mediatisation of memory. In: GARDE-HANSEN, Joanne; HOSKINS, Andrew; READING, Anna. Save as...digital memories. London: Pallgrave-Macmillan, 2009. p. 27-43.

LEROI-GOURHAN, André. O gesto e a palavra. vol. 1. Lisboa: Edições 70, 1990.

MANOVICH, Lev. The language of new media. Cambridge: MIT Press, 2001.

MANOVICH, Lev. Understanding hybrid media. 2001. Disponível em: <http://www.manovich.net>. Acesso em: 25 mai. 2009.

MANOVICH, Lev. What comes after remix. 2007. Disponível em: $<$ http://www.manovich.net $>$. Acesso em: 25 mai. 2009.

MANOVICH, Lev. Software takes command. 2008. Disponível em: <http://www.manovich.net>. Acesso em: 25 mai. 2009.

MUSSO, Pierre. A filosofia da rede. In: Parente, A. (Ed.). Tramas da rede: novas dimensões filosóficas, estéticas e políticas da comunicação. Porto Alegre: Sulina, 2004. 
OLIVEIRA, W. Mais que um inventário imagético do Youtube: uma possível leitura da memória na rede. (s/d). Disponível em: <http://www.bocc.ubi.pt>. Acesso em: 05 abr. 2010.

ROWE, S.; WERTSCH, J.; KOSYAEVA, T. Linking little narratives to big ones: narrative and public memory in history museums. In: Culture and Psychology, vol. 8, n. 1. 2002. p. 96-112.

RUPPEL, Marc. Narrative convergence, cross-sited productions and the archival dilemma. In: Convergence, vol.15, n. 3, 2009. p. 281-298.

SÁ, Alberto. A web 2.0 e a meta-memória. In: Actas do 5‥ SOPCOM. Braga: Centro de estudos de comunicação e Sociedade, 2008.

SANTAELLA, Lúcia. A estética das linguagens líquidas. In: ARANTES, Priscila; SANTAELLA, Lúcia. (Ed.) Estéticas tecnológicas: novos modos de sentir. São Paulo: Educ, 2008.

SANTOS, Myriam. Memory and narrative in social theory: the contributions of Jacques Derrida and Walter Benjamim. In: Time and Society, vol. 10, n. 2/3. 2001. p. 163-189.

SERRES, Michel. Hermes: uma filosofia das ciências. Rio de Janeiro: Graal, 1990.

SOUZA E SILVA, Adriana. Interfaces móveis de comunicação e subjetividade contemporânea: de ambientes de multiusuários como espaços (virtuais) a espaços (híbridos) como ambientes de multiusuários. Rio de Janeiro: UFRJ/CFCH/ECO, 2004.

TILL, K. Artistic and activist memory-work: approaching place-based practice. In: Memory studies, vol. 1, n. 1. 2008. p. 99-113.

TSCHUGGNALL, K.; WELZER, H. Rewriting memories: family recollections of the National Socialist past in Germany. In: Culture \& Psychology, vol. 8, n. 1. 2002. p. $130-145$.

VAN DIJCK, José. Mediated memories in the digital age. Stanford: Stanford University Press, 2007.

VERONESI, F.; GEMEINBOECK, P. Mapping footprints. In: Convergence, vol. 15, n. 3. 2009. p. 359-369. 